\title{
Erratum to: Effects of flavonoids on expression of genes involved in cell cycle regulation and DNA replication in human fibroblasts
}

\author{
Marta Moskot $^{1}$ - Joanna Jakóbkiewicz-Banecka ${ }^{2}$ - Elwira Smolińska ${ }^{2}$. \\ Ewa Piotrowska ${ }^{2} \cdot$ Grzegorz Wegrzyn $^{2} \cdot$ Magdalena Gabig-Cimińska $^{1}$
}

Published online: 28 October 2016

(C) Springer Science+Business Media New York 2016

\section{Erratum to: Mol Cell Biochem (2015) 407:97-109 DOI 10.1007/s11010-015-2458-3}

In the original publication of the article, acknowledgments section was incompletely published. The complete acknowledgments are provided in this erratum.
Acknowledgments This work was supported by National Science Centre (Project Grant Nos. UMO-2011/01/B/NZ1/ 03686, MAESTRO/2011/02/A/NZ1/00009). Marta Moskot was funded by National Science Centre Project Grant No. UMO-2014/12/T/NZ2/00538.

The online version of the original article can be found under doi:10.1007/s11010-015-2458-3.

Magdalena Gabig-Cimińska

m.gabig@biol.ug.edu.pl

1 Laboratory of Molecular Biology (affiliated with the University of Gdańsk), Institute of Biochemistry and Biophysics, Polish Academy of Sciences, Wita Stwosza 59, 80-308 Gdańsk, Poland

2 Department of Molecular Biology, University of Gdańsk, Wita Stwosza 59, 80-308 Gdańsk, Poland 